\title{
Determinants of Hesitancy Towards COVID-19 Vaccines in State of Kuwait: An Exploratory Internet-Based Survey
}

\author{
Najla Al-Ayyadhi iD \\ Marwa Mohsen Ramadan ${ }^{2}$ \\ Eman Al-Tayar ${ }^{3}$ \\ Radhia Al-Mathkouri ${ }^{3}$ \\ Shaimaa Al-Awadhi ${ }^{3}$ \\ 'Public Health Specialist, Directorate of \\ Public Health, Ministry of Health, Kuwait \\ City, State of Kuwait; ${ }^{2}$ Lecturer of \\ Community Medicine, Faculty of \\ Medicine for Girls, Al-Azhar University, \\ Cairo, Egypt; ${ }^{3}$ Public Health Physician, \\ Directorate of Public Health, Ministry of \\ Health, Kuwait City, State of Kuwait
}

Background: The coronavirus disease 2019 (COVID-19) pandemic has wrought havoc upon healthcare and economic systems worldwide. COVID-19 vaccines considered a beacon of hope for normal life to return. We wished to understand the willingness of people in Kuwait to be vaccinated against COVID-19.

Methods: An online, exploratory, cross-sectional study was conducted on 1618 January 2021 using a validated structured questionnaire to collect data from adults aged 18 years or older living in Kuwait by applying a "snowball sampling" method.

Results: A total of 7274 people received an online link of the survey on their smartphone or computer, and 6943 people enrolled in this study (95.4\%). Kuwaiti nationals represented $79.7 \%$ of the study cohort, $54.8 \%$ were aged $\geq 40$ years, and $66.7 \%$ were females. Hesitancy against a COVID-19 vaccine was remarkably high (74.3\%), with $50.8 \%$ not planning to take it and $23.5 \%$ not sure about taking it. The overall mean perception score was $3.4 \pm 2.8$, with $66.8 \%$ having a negative attitude towards a COVID-19 vaccine. Multiple logistic regression analysis of the factors affecting the decision to take a COVID-19 vaccine was done. The decision to take a COVID-19 vaccine was significantly positively associated with younger age $(\mathrm{OR}=1.219)$, being male (2.169), having a higher education level (1.362), vaccinated against seasonal influenza previously (2.706), being a non-Kuwaiti (1.329), being a healthcare worker (1.366), and working in the private sector (1.228). Options to encourage future COVID-19 vaccination were more studies showing the vaccine to be safe and efficacious (68.6\%), physician recommendation $(41.8 \%)$, mandatory travel requirements $(39.8 \%)$, if a family or friend vaccinated $(34.9 \%)$ and compulsory by government $(33.1 \%)$ or for employment $(29.8 \%)$.

Conclusion: Our data suggest that considerable vaccine hesitancy persists despite the widespread availability of highly efficacious and safe COVID-19 vaccines.

Keywords: COVID-19, vaccine acceptance, vaccine uptake, hesitancy, barriers

\section{Introduction}

Coronavirus disease 2019 (COVID-19) emerged in December 2019 in Wuhan, China. ${ }^{1}$ Subsequently, it has spread around worldwide, thereby compelling the World Health Organization (WHO) on 11 March 2020 to declare the COVID-19 outbreak to be a pandemic. ${ }^{2}$ By August 2021, there have been $>200$ million COVID-19 cases and $>4$ million COVID-19-based deaths worldwide. ${ }^{3}$ The first confirmed case in Kuwait was announced in February 2020, and the first death was reported in April 2020. ${ }^{3}$ The start of vaccination against COVID-19 was a beacon
Correspondence: Najla Al-Ayyadhi Public Health Department, Kuwait Ministry of Health, P.O. Box 17782 , Khaldeya, Kuwait City, 72458, State of Kuwait

Tel +96599644676

Email dr.najlaI00I@hotmail.com 
of hope for a return to normal life. Although the efficacy and safety of COVID-19 vaccines reaches $95 \%$ for preventing COVID-19, some people remain hesitant about being vaccinated against it. ${ }^{4}$ Reluctance to accept vaccination is not limited to COVID-19 vaccines. Doubts regarding the importance and safety of vaccines among a portion of the public have existed since the beginning of vaccination. ${ }^{5}$ An increasing number of people are unwilling to take recommended vaccines, ${ }^{6-9}$ a phenomenon referred to as "vaccine hesitancy" (VH). ${ }^{5}$

Vaccine hesitancy (VH) is defined as a delay in the acceptance, reluctance, or refusal of vaccination despite the availability of vaccination services. ${ }^{5,10} \mathrm{VH}$ has been identified by the WHO as one of the top-10 threats to global health in 2019. ${ }^{10}$ Although VH has existed among a small percentage of people for centuries, its harmful effects are likely to be more pronounced during the COVID-19 pandemic than ever before. ${ }^{10} \mathrm{VH}$ can be impacted by a wide range of contexts, individuals, and groups. It can also be influenced by vaccine-specific factors, including communication media, historical influences, religion/culture/gender/socioeconomic factors, politics, geographic barriers, experience of vaccination, risk perception, and the design of the vaccination program.

Information from social media has boosted the speed of information exchange worldwide significantly. ${ }^{10,11}$ Unfortunately, misinformation can also be spread via the same route. The WHO Director-General stated in February 2020 that "We're not just fighting an epidemic; we're fighting an infodemic". ${ }^{12}$ The latter refers to an excess of information, some correct and some not, which arises during a disease outbreak. It spreads across populations in a similar manner to a disease outbreak, ${ }^{11}$ via digital and physical information systems, thereby making it difficult for people to access reliable information when they need it. ${ }^{11,12}$ The creation of uncertainty is particularly harmful with respect to vaccination because doubt can lead to $\mathrm{VH}^{7}$ Research conducted in high-income countries suggests that there are five main individual-level determinants of VH: confidence; convenience (or constraints); complacency; risk calculation; collective responsibility. ${ }^{9,13}$ This framework is referred to as the "5C" model of VH drivers. ${ }^{13}$

"Confidence" denotes trust in the efficacy and safety of vaccines, the system that administers vaccination, and the motivation of people who decide on the need for vaccination. ${ }^{14}$ "Constraints" denote structural or psychological barriers to the conversion of vaccination intentions into uptake of vaccination. ${ }^{13}$ "Complacency" is said to occur if the perceived risks of vaccine-preventable diseases are low, and vaccination is not considered necessary. ${ }^{5}$ "Risk calculation" indicates a deliberate comparison of the risks of infection and vaccination from which a decision is derived. Individuals who score high in risk calculation perceive higher risks related to vaccination than for the infection. "Collective responsibility" refers to the willingness to protect others by one's own vaccination through population immunity. ${ }^{9}$

Several studies (especially in developed countries) have explored the prevalence of acceptance of COVID19 vaccines and their determinants. ${ }^{15-22}$ Studies in the USA conducted early in the COVID-19 pandemic found that $58-86 \%$ of adults reported that they were likely to be vaccinated against COVID-19. ${ }^{16,23-25}$ However, the rise of "fake news" during the COVID-19 pandemic has been acknowledged widely, ${ }^{25}$ and widespread misinformation about the pandemic may have been damaging to the public willingness to be vaccinated. ${ }^{24,26}$ In addition, the speed at which COVID-19 vaccines has been developed has been unparalleled, and this may have made the public more hesitant ${ }^{27,28}$ about accepting them. Four cross-sectional Internet-based surveys in the USA ${ }^{24,29-31}$ from April to May 2020 found that $58-69 \%$ of adults intended to be vaccinated against COVID-19, with higher percentages reported in Aprill $^{24}$ than in May. ${ }^{29-31}$ Another study ${ }^{18}$ analyzed biweekly survey data from a nationally representative longitudinal study to describe changes over time in the public's likelihood of getting a COVID-19 vaccine in the USA between April, November, and December 2020. The proportion of participants who stated that they were "somewhat likely" or "very likely" to get vaccinated declined from $74 \%$ to $56 \%$. Significant declines over time in the likelihood of seeking vaccination were observed for women and men of all ages, racial/ethnic, and educational subgroups. ${ }^{18}$ On average, the willingness to vaccinate declined from $71 \%$ in April to $53.6 \%$ in October 2020. This result was explained by an increase in the percentage of participants "undecided" about being vaccinated against COVID-19 (from 10.5\% to 14.4\%) and the portion of the sample unwilling to be vaccinated (from $18.5 \%$ to $32 \%){ }^{32}$ Reports in early-2020 showed a higher level of VH compared with that in reports in 2021. ${ }^{33-35}$ This observation may be related to the growing evidence of the efficacy and safety of currently used vaccines and their swift effect on pandemic control, as shown in countries with high vaccine coverage. ${ }^{19,36}$ 
The Kuwaiti government, like other governments worldwide, implemented rigorous measures to prevent the spread of the virus that causes COVID-19: severe acute respiratory syndrome-coronavirus 2 (SARS-CoV-2). The Kuwaiti government suspended workplace attendance, schools, universities, public events, recreation in public parks, social gatherings, and closed its borders. The entire country was on "lockdown" several times. ${ }^{2}$ After the WHO listed and approved vaccines against COVID-19 for emergency use, only two vaccines were approved in Kuwait: Pfizer-BioNTech and Oxford-AstraZeneca. The COVID-19 vaccination program started in January 2021 with the hope to achieve community-based immunity for $>70 \%$ of the population through mass vaccination. ${ }^{37-39}$

To accomplish this noble aim, it was crucial to understand the perceptions of the general population regarding acceptance of COVID-19 vaccines. The purpose of this exploratory study was to understand the public willingness to uptake COVID-19 vaccines in Kuwait. The primary objective was to estimate the acceptance and hesitancy of adults in Kuwait to accept COVID-19 vaccines. The secondary objective was to identify factors associated with the acceptance or rejection of COVID-19 vaccination. Our study provides public-health officials with the data to develop appropriate vaccination strategies and immunization programs against COVID-19.

\section{Materials and Methods}

\section{Study Design, Setting, and Population}

An online, exploratory, analytical, descriptive crosssectional study was conducted on 16-18 January 2021, the same week that the campaign of COVID-19 vaccination was started in Kuwait. Participants were eligible if they were 18 years of age or older, living in Kuwait, could read Arabic, and had access to the Internet via a computer or smartphone. The study investigators shared the survey link in social-media platforms (mainly via WhatsApp ${ }^{\mathrm{TM}}$ and Twitter ${ }^{\mathrm{TM}}$ ) and asked participants to further disseminate the survey to their peers. On receiving and clicking the survey link, participants were directed automatically to a page for obtaining informed consent, which contained a short message describing the purpose of the study followed by a question. If they agreed to participate, they were directed to the survey questions. If they did not agree, then the form was terminated.

\section{Data-Collection Tools}

Data were collected using a structured questionnaire adapted from earlier studies tackling similar objectives. ${ }^{20,40}$ Experts in public health working at the College of Public Health assessed the content and clarity of the questionnaire. The final questionnaire was developed based on the Cronbach's alpha value $(>0.70) .{ }^{20}$ Two epidemiology experts reviewed all questionnaire items independently. Their feedback was considered in the final version of the questionnaire. The investigators pre-tested the questionnaire on 30 people in Kuwait before conducting the study to ensure clarity and understanding. Minimal modifications were made accordingly, and those people were excluded from the study.

All questions were close-ended, with tick-boxes provided for responses. The questionnaire consisted of five parts. Part 1 was based on sociodemographic data (age, sex, nationality, governorate residence, education, occupation, marital status, number of children, having a chronic disease, and being vaccinated against influenza). Part 2 focused on measuring participants' perception and willingness to accept a COVID-19 vaccine through four questions: "Do you think that COVID-19 vaccination, whenever available, will be safe?" "Do you think that COVID-19 vaccination, whenever available, will be effective?" "Do you think that the best way to avoid the complications of COVID-19 is by being vaccinated?" and "When COVID-19 vaccination is available, Are you planning to get vaccinated against COVID-19? Each question was answered on a three-level Likert scale ("No", "Not sure", "Yes"), the items were coded 0,1 , and 2, respectively, and summed for a possible range of $0-8$. Accordingly, the mean perception score was calculated, with $\geq 4$ considered denoting a "positive" perception and $<4$ reflecting a "negative" perception. ${ }^{40}$

People who did not intend to take or who were not sure about COVID-19 vaccination were directed to Part 3, which focused on the main concerns regarding uptake of a COVID19 vaccine. Reasons included believing: that it is not efficacious; in conspiracy theories about COVID-19 vaccines; that COVID-19 vaccination is not needed because of robust health and youth; following health instructions (eg washing hands) will be adequate. Other reasons included being worried about side-effects, having contracted COVID-19 previously, or being needle-phobic. These were closed-end questions with the options of "Yes" and "No" answers for each item. ${ }^{40}$

Part 4 focused on the best solutions to encourage vaccine uptake according to the participant's opinion (eg 
mandatory COVID-19 vaccination for travel, government employment, or private employment). These were closedend questions with the options "Agree", "Not sure", and "Don't agree" answers for each item. Part 5 was based on the tools affecting perception towards COVID-19 vaccination. These tools included official press releases from the Ministry of Health, social media, traditional media, as well as influence from the family and friends. The participants could choose more than one answer. The study questionnaire written in English is shown in Supplementary File 1.

\section{Statistical Analyses}

Data analyses were undertaken using SPSS 25 (IBM, Armonk, NY, USA). Descriptive analyses were conducted to calculate frequencies and proportions of categorical variables. Continuous variables are presented as mean \pm standard deviation (SD). The primary outcome of this study was the intention for COVID-19 vaccination, which had three possible responses: "Yes", "Not sure", and "No". However, dichotomous classification was considered to assess $\mathrm{VH}$ by dividing the study population into two groups: (i) participants with $\mathrm{VH}$ who rejected COVID-19 vaccination or who were undecided ("No" or "Not sure" responses); (ii) participants with a clear intention to receive the vaccine ("Yes" response). ${ }^{15,19,40}$

A cross-tabulation analysis was undertaken using the chi-square test or Fisher's exact test to assess categorical variables. Continuous variables were analyzed via the Student's $t$-test or one-way analysis of variance. $p<0.05$ (two-tailed) was considered significant. Multivariate binary logistic regression analysis was conducted to predict the determinants of COVID-19-vaccine acceptance. Stepwise backward selection with $p=0.25$ was employed to select the final model in which the explanatory variables were: age; sex; nationality; governorate residence; occupation; educational level; having children; history of seasonal influenza vaccination; family member/friend had contracted COVID-19. Adjusted odds ratios (ORs) and their related $95 \%$ confidence intervals (CIs) were estimated. $p<0.05$ was considered significant.

\section{Ethics Approval}

This study was conducted in accordance with the declaration of Helsinki. Ethical approval of the study protocol was granted (MoH/REC/1605) from the Ethical Committee For Medical Research at the Ministry of Health in Kuwait in December 2020. Written informed consent was obtained from all individuals who participated in our study.

\section{Results}

A total of 6943 participants agreed to take our survey and were included in the study. A total of 7274 people received the Internet link for the survey, therefore participation was 95.4\%. However, 355 people stopped after section 3 and did not continue to sections 4 and 5 (Figure 1).

\section{Sociodemographic Characteristics of Study Participants}

Table 1 shows the sociodemographic characteristics of study participants. Most were Kuwaiti (79.9\%), 54.8\% were aged $>40$ years, $66.7 \%$ were female, and $66.2 \%$ were university graduates. Only $13 \%$ were healthcare workers and $70.9 \%$ did not have a chronic disease. In addition, $37.0 \%$ had received vaccination against influenza previously, $71.4 \%$ had a relative or friend who had contracted COVID-19, and $28.2 \%$ had a relative or friend who had died from it.

\section{An Overall Low Prevalence of Acceptance of COVID-19 Vaccination Among the Adult Population in Kuwait}

Perception regarding uptake and acceptance of a COVID19 vaccine is demonstrated in Table 2. We found that $74.3 \%$ of participants were hesitant about it: $50.8 \%$ were not planning to take it, and $23.5 \%$ were unsure about being vaccinated against COVID-19. The overall perception score (mean $\pm \mathrm{SD}$ ) was $3.4 \pm 2.8$. Accordingly, $66.8 \%$ of respondents had a negative perception towards COVID-19 vaccination. The factors affecting the decision of COVID19-vaccine uptake are presented in Table 3. Sex, nationality, governorate residence, education level, occupation, history of seasonal influenza vaccination, and having a relative/friend who had contracted COVID-19 carried a significant difference $(P<0.05)$ between those who agreed to take the vaccine and those who were hesitant.

Multivariate binary logistic regression analysis of the factors affecting the decision to take a COVID-19 vaccine revealed a positive association with being male $(\mathrm{OR}=$ 2.169, 95\% CI $=1.915-2.457, \mathrm{P}<0.001)$, being a college graduate $(1.044,869-1.68,<0.001)$ being a postgraduate $(1.362,1.104-1.681,0.004)$, having seasonal influenza vaccination previously $(2.706,2.396-3.056$, $<0.001)$, being non-Kuwaiti (1.329, 1.131-1.561, 0.001), being a healthcare worker $(1.366,1.140-1.636,<0.001)$, and working in the private sector $(1.228,1.008-1.497$, 


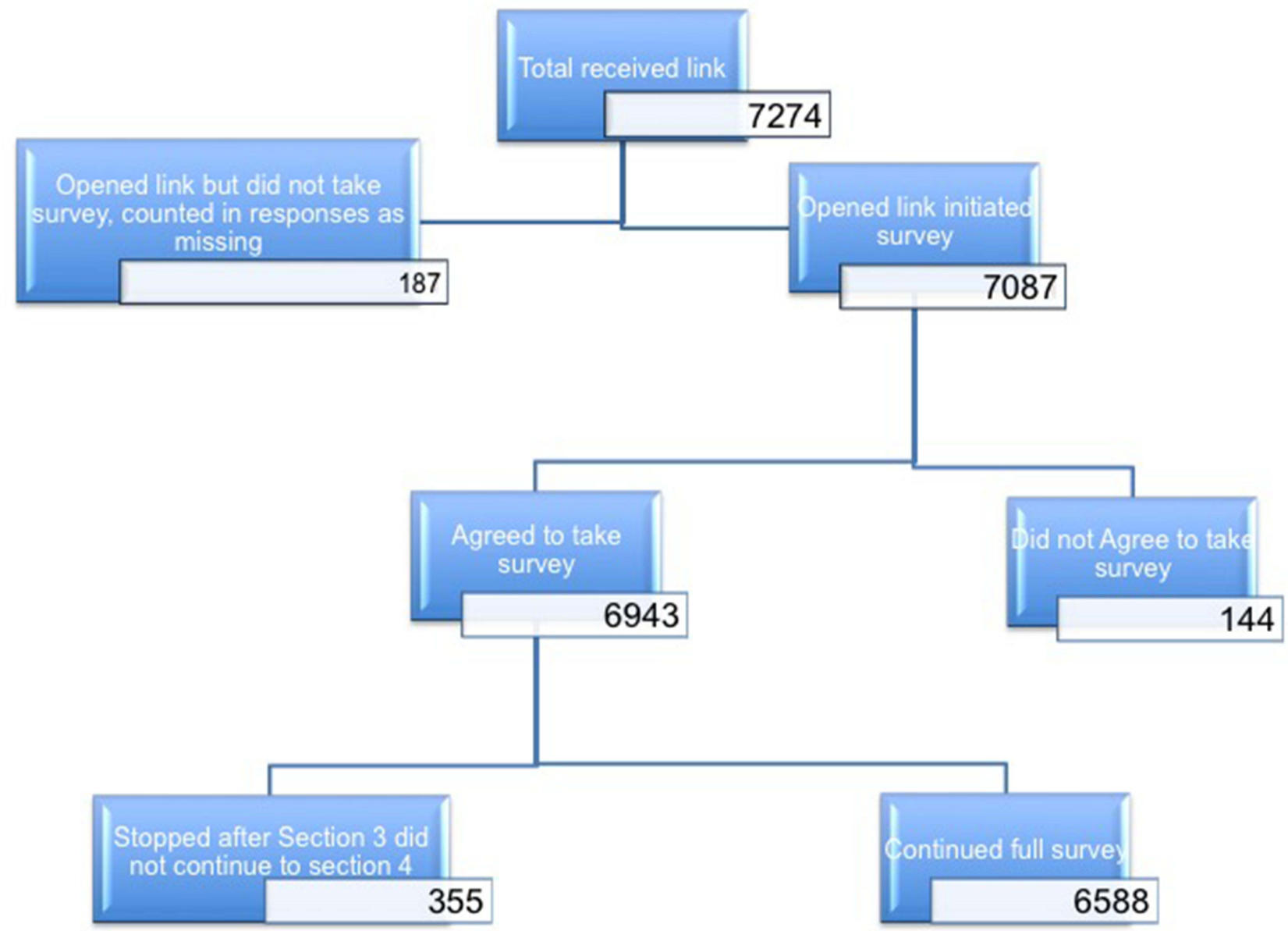

Figure I Participation rate.

$<0.001)$. Conversely, older age, living in frontier governorates (Ahmadi and Jahra), and having a family member or friend who had contracted COVID-19 were significantly negatively associated with acceptance of COVID-19 vaccination or having no intention to take it (Table 4).

\section{Barriers Against COVID-19 Vaccination Among the Adult Population in Kuwait}

The main barriers to COVID-19-vaccine uptake are shown in Figure 2. Most (96.7\%) respondents were concerned about the side-effects of the COVID-19 vaccine, $76.4 \%$ did not believe the vaccine would stop SARS-CoV-2 infection, $72.3 \%$ thought that they did not need the COVID-19 vaccine because they were following health instructions appropriately (washing hands and wearing a face covering and gloves), 55.1\% believed that COVID-19 vaccination was a conspiracy, $42.7 \%$ thought that they did not need the COVID-19 vaccine because they are young and healthy, $28.9 \%$ did not believe in vaccination at all, $27.3 \%$ were needle-phobic, $18.9 \%$ believed that they had contracted COVID-19 but were not tested, and $12.9 \%$ tested positive for COVID-19.

The difference in the barriers to COVID-19 vaccination were explored further between those who rejected vaccination ("No" response) and those who were undecided ("Not sure" response). Both groups were found to be highly concerned about safety (96.6\%) and side-effects (95.0\%). Additionally, there were significant differences between the two groups with regard to: believing conspiracy theories; not believing in vaccination at all or that the vaccine would stop COVID-19; not needing the vaccine because they were following health instructions; feeling healthy; being needle-phobic; having contracted COVID19 previously (Table 5).

\section{Options to Encourage People to Have COVID-19 Vaccination in the Future}

Options to encourage future decisions to take a COVID-19 vaccine are shown in Figure 3. Most respondents (68.6\%) 
Table I Sociodemographic Characteristics of the Participants

\begin{tabular}{|c|c|c|}
\hline \multirow[t]{2}{*}{ Items } & \multicolumn{2}{|c|}{$N=6943$} \\
\hline & No. & $\%$ \\
\hline \multicolumn{3}{|l|}{ Age groups in years } \\
\hline$\bullet 18-29$ & 1124 & 16.1 \\
\hline • 30-39 & 2020 & 29.1 \\
\hline - 40-59 & 2913 & 42.0 \\
\hline$\bullet \geq 60$ & 886 & 12.8 \\
\hline \multicolumn{3}{|l|}{ Gender } \\
\hline - Male & 2309 & 33.3 \\
\hline - Female & 4634 & 66.7 \\
\hline \multicolumn{3}{|l|}{ Nationality } \\
\hline • Kuwaiti & 5533 & 79.7 \\
\hline - Non-Kuwaiti & 1410 & 20.3 \\
\hline \multicolumn{3}{|l|}{ Governorates } \\
\hline • Capital & 2317 & 33.4 \\
\hline - Hawally & 2308 & 33.2 \\
\hline - Farwanya & 862 & 12.4 \\
\hline • Ahmadi & 1195 & 17.2 \\
\hline • Jahra & 261 & 3.8 \\
\hline \multicolumn{3}{|l|}{ Education Level } \\
\hline$\bullet \leq 12$ years & 886 & 12.8 \\
\hline - College/University Graduate & 4597 & 66.2 \\
\hline - Higher Education & 1460 & 21.0 \\
\hline \multicolumn{3}{|l|}{ Occupation } \\
\hline - Healthcare workers & 902 & 13.0 \\
\hline - Government sector & 2493 & 35.9 \\
\hline - Private sector & 1291 & 18.6 \\
\hline - Unemployed (including retirees, students, and housewives) & 2257 & 32.5 \\
\hline \multicolumn{3}{|l|}{ Marital Status } \\
\hline - Married & 4914 & 70.8 \\
\hline - Single (including divorced, widowed) & 2029 & 29.2 \\
\hline \multicolumn{3}{|l|}{ Having Children } \\
\hline - Yes & 5065 & 73.0 \\
\hline$\bullet$ No & 1878 & 27.0 \\
\hline \multicolumn{3}{|l|}{ Having chronic disease } \\
\hline - Yes & 2018 & 29.1 \\
\hline - No & 4925 & 70.9 \\
\hline \multicolumn{3}{|l|}{ Previous seasonal influenza vaccine } \\
\hline • Yes & 2570 & 37.0 \\
\hline$\bullet$ No & 3934 & 56.7 \\
\hline - Not sure & 439 & 6.3 \\
\hline \multicolumn{3}{|l|}{ Family member or a friend had COVID-19 infection } \\
\hline - Yes & 4958 & 71.4 \\
\hline - No & 1985 & 28.6 \\
\hline \multicolumn{3}{|l|}{ Family member or a friend died of COVID-19 infection } \\
\hline • Yes & 1955 & 28.2 \\
\hline - No & 4988 & 71.8 \\
\hline
\end{tabular}

would agree to take the COVID-19 vaccine if more studies showed it to be safe and efficacious, whereas $41.8 \%$ would take it if their family physician recommended it, if it was a mandatory travel requirement (39.8\%), if a family member or friend had been vaccinated $(34.9 \%)$, the government made vaccination compulsory (33.1\%), it was a mandatory job requirement $(29.8 \%)$, or if COVID-19 vaccination could be delivered via a non-injection route $(24.0 \%)$. Conversely, $26.6 \%$ said that they would not take the vaccine under any circumstances.

The difference between hesitant participants (those who rejected vaccination or undecided), and people willing to take the COVDI-19 vaccine with regard to suggested options was explored further. Most of the people who wished to take the COVID-19 vaccine agreed that the above-mentioned options would encourage COVID-19vaccine uptake. Also, $58.1 \%$ of respondents who provided "No" or "Not sure" responses agreed that further studies on safety and efficacy would encourage COVID-19vaccine uptake. Fewer than $25 \%$ of this group agreed that the above-mentioned options would encourage COVID-19-vaccine uptake, and $36.5 \%$ said that they would not take it under any circumstances (Table 6).

\section{Tools Affecting Perception Towards COVID-1 9 Vaccines and Sources of Knowledge}

We found that reading the latest articles in medical journals $(63.1 \%)$, reading official press releases from the Ministry of Health (61.6\%), and social media (eg WhatsApp, Twitter, Snapchat ${ }^{\mathrm{TM}}$, Instagram $\left.{ }^{\mathrm{TM}}\right)(35.9 \%)$ were the most popular tools affecting perception towards COVID-19 vaccination (Figure 4).

\section{Discussion}

Most estimates to date indicate that vaccination of $80 \%$ of the general population will be required to end the COVID-19 pandemic. ${ }^{17}$ The COVID-19 vaccine was launched in Kuwait in January 2021, but the number of people who registered to receive it was far below what is required to develop "herd immunity". Hence, the current study was conducted to understand public willingness to take the COVID-19 vaccine among the adult population in Kuwait. Remarkably, we found low acceptance and high hesitancy of COVID-19 
Table 2 COVID-19 Vaccine Perception

\begin{tabular}{|c|c|c|c|}
\hline \multirow[t]{3}{*}{ Studied Groups Item } & \multicolumn{3}{|c|}{$N=6943$} \\
\hline & No & Not sure & Yes \\
\hline & $\mathbf{N}(\%)$ & $\mathbf{N}(\%)$ & $\mathbf{N}(\%)$ \\
\hline - Do you think that COVID-19 vaccination, whenever available, would be safe? & $2535(36.5 \%)$ & $3025(43.6 \%)$ & I 383 (19.9\%) \\
\hline - Do you think that COVID-19 vaccination, whenever available, would be effective? & $2070(29.8 \%)$ & $3289(47.4 \%)$ & $1584(22.8 \%)$ \\
\hline - Do you think that the best way to avoid the complications of COVID- 19 is by being vaccinated? & $2823(40.7 \%)$ & $1895(27.3 \%)$ & 2225 (32.0\%) \\
\hline - If COVID-19 vaccination is available, are you planning to get it? & $3528(50.8 \%)$ & $1635(23.5 \%)$ & $1780(25.6 \%)$ \\
\hline - Perception Score Mean $\pm(S D)^{*}$ & \multicolumn{3}{|c|}{$3.4 \pm(2.8)$} \\
\hline - Negative perception & \multicolumn{3}{|c|}{$4635(66.8 \%)$} \\
\hline - Positive perception & \multicolumn{3}{|c|}{$2308(33.2 \%)$} \\
\hline
\end{tabular}

Notes: *Each question answers on 3-likert scale (No, Not sure, Yes) and the items were summed for a possible range of 0-8. Accordingly perception score was calculated according to the mean score: and participants with $\geq 4$ considered as of positive perception and those $<4$ as negative perception.

vaccination in $74.3 \%$ of respondents. People were either not willing to take the vaccine $(50.8 \%)$ or were not sure about taking it $(23.5 \%)$, and only $25.6 \%$ were willing to be vaccinated. These percentages are in accordance with reports from Kuwait and Middle East countries that documented a low prevalence of COVID-19vaccine acceptance. ${ }^{17,35,41-43}$ However, our study results are in contrast with data from WHO studies in 19 countries that found differences in the prevalence of acceptance ranging from $\sim 90 \%$ (in China) to $<55 \%$ (in Russia). ${ }^{16}$ Moreover, a lower prevalence of acceptance was detected in our study than that reported from studies in Kuwait $\left(53.1 \%^{21}\right.$ and $\left.67 \%^{22}\right)$, the UK $(82 \%),{ }^{44}$ France $(76 \%),{ }^{45}$ USA $\left(67 \%{ }^{31}\right.$ and $\left.53 \%{ }^{32}\right)$, and Saudi Arabia (67\%). ${ }^{20}$

In the current study, greater $\mathrm{VH}$ was associated with being female, $>40$ years of age, a Kuwaiti citizen, lower education level, unemployed or working in governmental sectors, and never having influenza vaccination. These data are in accordance with results from studies in the USA, ${ }^{31}$ Jordan, ${ }^{46}$ Kuwait, $^{21,22}$ Saudi Arabia, ${ }^{20}$ and Qatar. ${ }^{47}$ Females were more likely to report that they would not take the COVID-19 vaccine and having a more negative perception than that in males, and the likelihood of having COVID-19 vaccination was lower among women than that in men. Furthermore, in line with recent findings from Kuwait, ${ }^{22}$ Saudi Arabia, ${ }^{20}$ Qatar, ${ }^{47}$ and the UK, ${ }^{44}$ we discovered that non-Kuwaiti residents were more likely to accept COVID-19 vaccination (37.1\%) compared with Kuwaiti citizens (22.7\%). Robertson and colleagues found Pakistani/Bangladeshi groups living in the UK had high levels of $\mathrm{VH}^{4}{ }^{44}$
Older people ( $>40$ years; $24.6 \%$ ) were less likely to take the COVID-19 vaccine compared with younger people (18-39 years; $26.9 \%$ ). This observation is in accordance with findings from Saudi Arabia, ${ }^{20}$ and Jordan. ${ }^{15}$ This alarming finding represents an area of concern because older people are at a higher risk from the morbidity and mortality of COVID19 , and are a priority group to receive a COVID-19 vaccine. Targeting this age group with appropriate interventions is crucial in reducing the COVID-19 burden. ${ }^{15}$ However, studies have reported that older people ( $>50$ years) are more likely to take COVID-19 vaccines..$^{18,20,24,31,44}$ A possible explanation for this observation maybe that younger people are more frustrated with social restrictions and curfews associated with the COVID-19 pandemic, and would be more willing to be vaccinated. Further, younger people may be more accustomed and trusting of science and technology in contrast to their older counterparts. In addition, suspension of academic studies may negatively affect the academic performance of school-aged children and university students, so they may be more impatient to bring an end to the pandemic and more accepting of vaccination. ${ }^{40}$

Occupation was linked to acceptance of COVID-19 vaccination. Healthcare workers were more likely to accept the COVID-19 vaccine and to have a more positive perception with vaccination than other groups. Unemployed people or those working in governmental sectors were less likely to accept the COVID-19 vaccine and more likely to have a negative perception of it. The conspicuous differences in COVID-19-vaccine acceptance between the general public and healthcare workers has been reported in studies from China $^{48}$ and Poland, ${ }^{49}$ and showed a higher prevalence of acceptance among healthcare workers in comparison with 
Table 3 Factors Affecting COVID-19 Vaccine Uptake Decision

\begin{tabular}{|c|c|c|c|}
\hline \multirow[t]{2}{*}{ Studied Groups Factors } & \multicolumn{2}{|c|}{ COVID-19 Vaccine Uptake Decision } & \multirow[t]{2}{*}{$P$-value } \\
\hline & $\begin{array}{c}\text { No/ Not Sure } n .=5163 \\
\text { N (\%) }\end{array}$ & $\begin{array}{c}\text { Yes } n_{.}=\mid 780 \\
N(\%)\end{array}$ & \\
\hline \multicolumn{4}{|l|}{ Age groups in years } \\
\hline - 18-39 & $2297(73.1 \%)$ & $847(26.9 \%)$ & $0.024 *$ \\
\hline$\bullet \geq 40$ & $2866(75.4 \%)$ & $933(24.6 \%)$ & \\
\hline \multicolumn{4}{|l|}{ Gender } \\
\hline - Male & $\mid 428$ (6I.8\%) & 881 (38.2\%) & $<0.00 I^{*}$ \\
\hline - Female & $3735(80.6 \%)$ & 899 (19.4\%) & \\
\hline \multicolumn{4}{|l|}{ Nationality } \\
\hline - Kuwaiti & $4276(77.3 \%)$ & 1257 (22.7\%) & $<0.00 I^{*}$ \\
\hline - Non-Kuwaiti & $887(62.9 \%)$ & $523(37.1 \%)$ & \\
\hline \multicolumn{4}{|l|}{ Governorates } \\
\hline - Capital & $1769(76.3 \%)$ & $548(23.7 \%)$ & $<0.00 I^{*}$ \\
\hline - Hawally & $1614(69.9 \%)$ & $694(30.1 \%)$ & \\
\hline - Farwanya & $646(74.9 \%)$ & $216(25.1 \%)$ & \\
\hline - Ahmadi & $933(78.1 \%)$ & $262(21.9 \%)$ & \\
\hline - Jahra & 201 (77.0\%) & $60(23.0 \%)$ & \\
\hline \multicolumn{4}{|l|}{ Education Level } \\
\hline$\bullet \leq 12$ years education & $679(76.6 \%)$ & $207(23.4 \%)$ & $<0.00 I^{*}$ \\
\hline - University & $3532(76.8 \%)$ & 1065 (23.2\%) & \\
\hline - Higher Education & 952 (65.2\%) & $508(34.8 \%)$ & \\
\hline \multicolumn{4}{|l|}{ Occupation } \\
\hline - Healthcare workers & 591 (65.5\%) & $311(34.5 \%)$ & $<0.00 I^{*}$ \\
\hline - Government sector & 1956 (78.5\%) & $537(21.5 \%)$ & \\
\hline - Private sector & $827(64.1 \%)$ & $464(35.9 \%)$ & \\
\hline - Unemployed ${ }^{\mathrm{a}}$ & $1789(79.3 \%)$ & $468(20.7 \%)$ & \\
\hline \multicolumn{4}{|l|}{ Marital Status } \\
\hline - Married & $3646(74.2 \%)$ & 1268 (25.8\%) & 0.621 \\
\hline - Single (including divorced, widowed) & 1517 (74.8\%) & $512(25.2 \%)$ & \\
\hline \multicolumn{4}{|l|}{ Having Children } \\
\hline - No & $|36|(72.5 \%)$ & $517(27.5 \%)$ & $0.028 *$ \\
\hline • Yes & $3802(75.1 \%)$ & I 263 (24.9\%) & \\
\hline \multicolumn{4}{|l|}{ Having chronic disease } \\
\hline - No & $3647(74.1 \%)$ & 1278 (25.9\%) & 0.352 \\
\hline - Yes & $1516(75.1 \%)$ & $502(24.9 \%)$ & \\
\hline \multicolumn{4}{|l|}{ Previous seasonal influenza vaccine } \\
\hline - No & $3545(81.1 \%)$ & $828(18.9 \%)$ & $<0.00 I^{*}$ \\
\hline - Yes & $1618(63.0 \%)$ & $952(37.0 \%)$ & \\
\hline \multicolumn{4}{|c|}{ Family member or a friend had COVID-19 infection } \\
\hline - No & $1397(70.4 \%)$ & $588(29.6 \%)$ & $<0.00 I^{*}$ \\
\hline - Yes & $3766(76.0 \%)$ & $1192(24.0 \%)$ & \\
\hline \multicolumn{4}{|c|}{ Family member or a friend died of COVID-19 infection } \\
\hline - No & $3686(73.9 \%)$ & $1302(26.1 \%)$ & 0.156 \\
\hline - Yes & I 477 (75.5\%) & $478(24.5 \%)$ & \\
\hline
\end{tabular}

Notes: Row percentages. ${ }^{a}$ Unemployed (including retirees, students, and housewives). - $* \mathrm{P}<0.05$, that is, significant difference between hesitant and willing to take vaccine at the $5 \%$ level of significance.

that in the general population. However, a paradoxical increase in VH has been noted previously among healthcare workers, who should be instilling confidence in immunization programs. ${ }^{50}$
Respondents with a high education level ${ }^{16,31,44,46}$ or who had seasonal vaccination against influenza previously ${ }^{16,21,22,51}$ were predictors for acceptance of COVID-19 vaccination, and to have a positive perception of it. Conversely, respondents 
Table 4 Multiple Logistic Regression Analysis for Factors Affecting Decision Uptake of COVID-19 Vaccine

\begin{tabular}{|c|c|c|c|}
\hline \multirow[t]{2}{*}{ Determinants } & \multicolumn{3}{|c|}{ Decision Uptake of COVID- 19 Vaccine Yes $=1780$, No $/$ Not Sure $=5163$} \\
\hline & B & Adjusted Odds Ratio (95\% Cl) & p-value \\
\hline $\begin{array}{l}\text { - } \geq 40 \text { years old } \\
\text { - Male Gender } \\
\text { - Education Level } \\
\text { - High school } \\
\text { - University } \\
\text { - Post graduate } \\
\text { - Occupation } \\
\text { - Unemployed a } \\
\text { - Government sector } \\
\text { - Private sector } \\
\text { - Healthcare workers } \\
\text { - Previous seasonal influenza vaccine } \\
\text { - Kuwaiti Nationality } \\
\text { - Governorates } \\
\text { - Capital } \\
\text { - Hawally } \\
\text { - Farwanya } \\
\text { - Ahmadi } \\
\text { - Jahra }\end{array}$ & $\begin{array}{l}0.520 \\
0.426 \\
-0.071\end{array}$ & 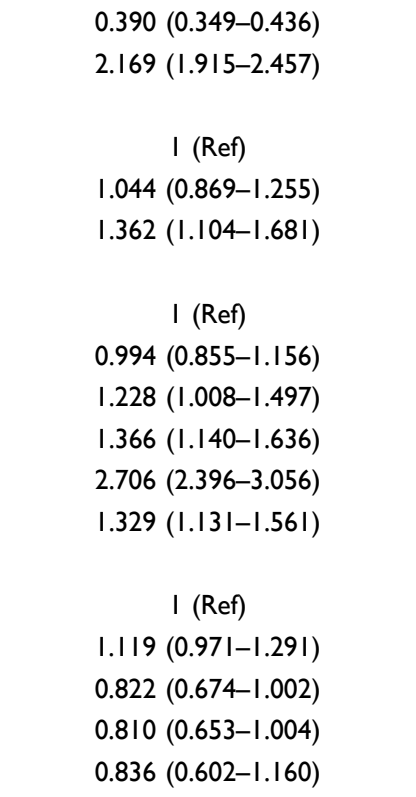 & $\begin{array}{c}0.00 I^{*} \\
<0.001 * \\
<0.001 *\end{array}$ \\
\hline - Family member or a friend had COVID-I9 infection & -0.154 & $0.844(0.743-0.958)$ & $0.009 *$ \\
\hline
\end{tabular}

Notes: anemployed (including retirees, students, and housewives). The variables included in the equation: age, gender, nationality, residence governorate, occupation, educational level, having children, history of seasonal flu vaccination and family member or a friend had COVID-19 infection, * $\mathrm{P}<0.05$, that is, significant difference between hesitant and willing to take vaccine at the $5 \%$ level of significance.

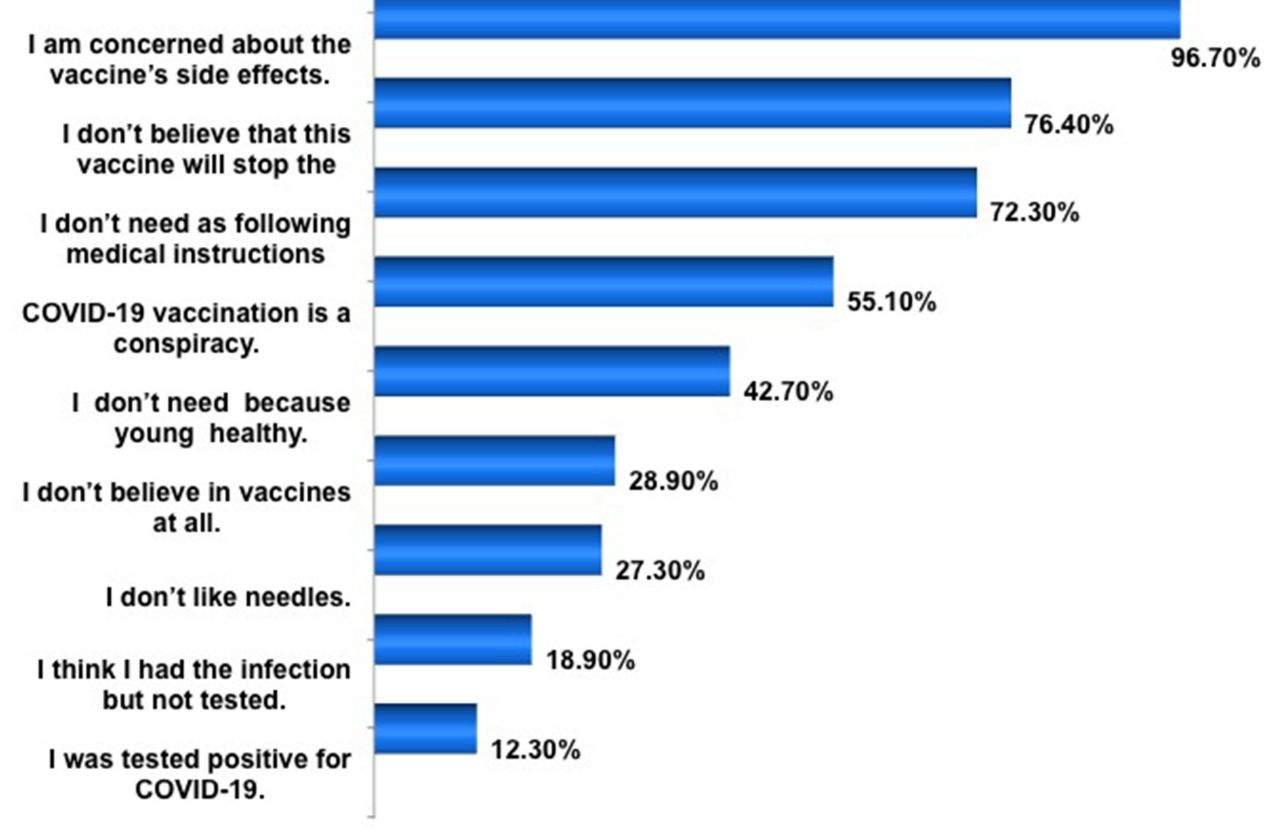

Figure 2 Main barriers regarding hesitancy of COVID-19 vaccine uptake. 
Table 5 Main Barriers of COVID-19 Vaccine Uptake

\begin{tabular}{|c|c|c|c|c|}
\hline \multirow[t]{2}{*}{ Barriers/Concerns } & \multirow[t]{2}{*}{$\begin{array}{l}\text { Total, } \\
N=5163(\%)\end{array}$} & \multicolumn{3}{|c|}{$\begin{array}{l}\text { Hesitancy to Take COVID-19 Vaccine } \\
\text { (No/ Not Sure) }\end{array}$} \\
\hline & & $\begin{array}{l}\text { No, } 3528 \\
\text { n (\%) }\end{array}$ & $\begin{array}{l}\text { Not Sure, } \\
1635 \text { n (\%) }\end{array}$ & P value \\
\hline - I am concerned about the vaccine's side effects. & $4962(96.1 \%)$ & 3409 (96.6\%) & 1553 (95.0\%) & $0.005^{*}$ \\
\hline - I do not believe that this vaccine will stop the infection. & 3944 (76.4\%) & 2960 (83.9\%) & $984(60.2 \%)$ & $<0.00 I^{*}$ \\
\hline $\begin{array}{l}\text { - I do not need the vaccine because I do all the right things (wash hands } \\
\text { and wear mask and gloves). }\end{array}$ & $3731(72.3 \%)$ & $2890(81.9 \%)$ & $841(51.4 \%)$ & $<0.00 I^{*}$ \\
\hline - COVID-19 vaccination is a conspiracy. & $2847(55.1 \%)$ & $2394(67.9 \%)$ & $453(27.7 \%)$ & $<0.00 I^{*}$ \\
\hline - I do not need the vaccine because I am young and healthy. & $2206(42.7 \%)$ & $1784(50.6 \%)$ & $422(25.8 \%)$ & $<0.00 I^{*}$ \\
\hline - I do not believe in vaccines at all. & $|49|$ (28.9\%) & 1277 (36.2\%) & $214(13.1 \%)$ & $<0.00 I^{*}$ \\
\hline - I do not like needles. & $1412(27.3 \%)$ & $996(28.2 \%)$ & $416(25.4 \%)$ & $0.037^{*}$ \\
\hline - I do not need the vaccine because I think I had the infection earlier. & $974(18.9 \%)$ & $763(21.6 \%)$ & $211(12.9 \%)$ & $<0.00 I^{*}$ \\
\hline - I do not need the vaccine because I was tested positive for COVID-I9. & $633(12.3 \%)$ & $482(13.7 \%)$ & $15 \mid(9.2 \%)$ & $<0.00 I^{*}$ \\
\hline
\end{tabular}

Notes: *The level of significance was $\mathrm{P}<0.05$.

who had a family member or friend who contracted COVID19 reported that they would not take the vaccine, and had a negative attitude regarding COVID-19 vaccination. Further studies are needed to ascertain the reasons for these findings.

The key barriers that might lead people not to accept uptake of a COVID-19 vaccine centered around its safety, side-effects, and concerns that it would not stop SARS-CoV-2 infection. Such barriers have been reported in various studies across different time periods and geographic locations. ${ }^{15,32,40,45,52,53}$ Conspiracy theories have spread very rapidly worldwide via social-media platforms. ${ }^{25,54,55}$ This was a major factor influencing the intention to be vaccinated against COVID-19 in the current study. An embrace of conspiratorial beliefs was prevalent from the early days of the COVID-19 pandemic and, subsequently, was extended to involve COVID-19 vaccination. ${ }^{25,41-43,56}$ Furthermore, nearly three-quarters of VH-respondents thought they did not need a COVID-19 vaccine because they were following

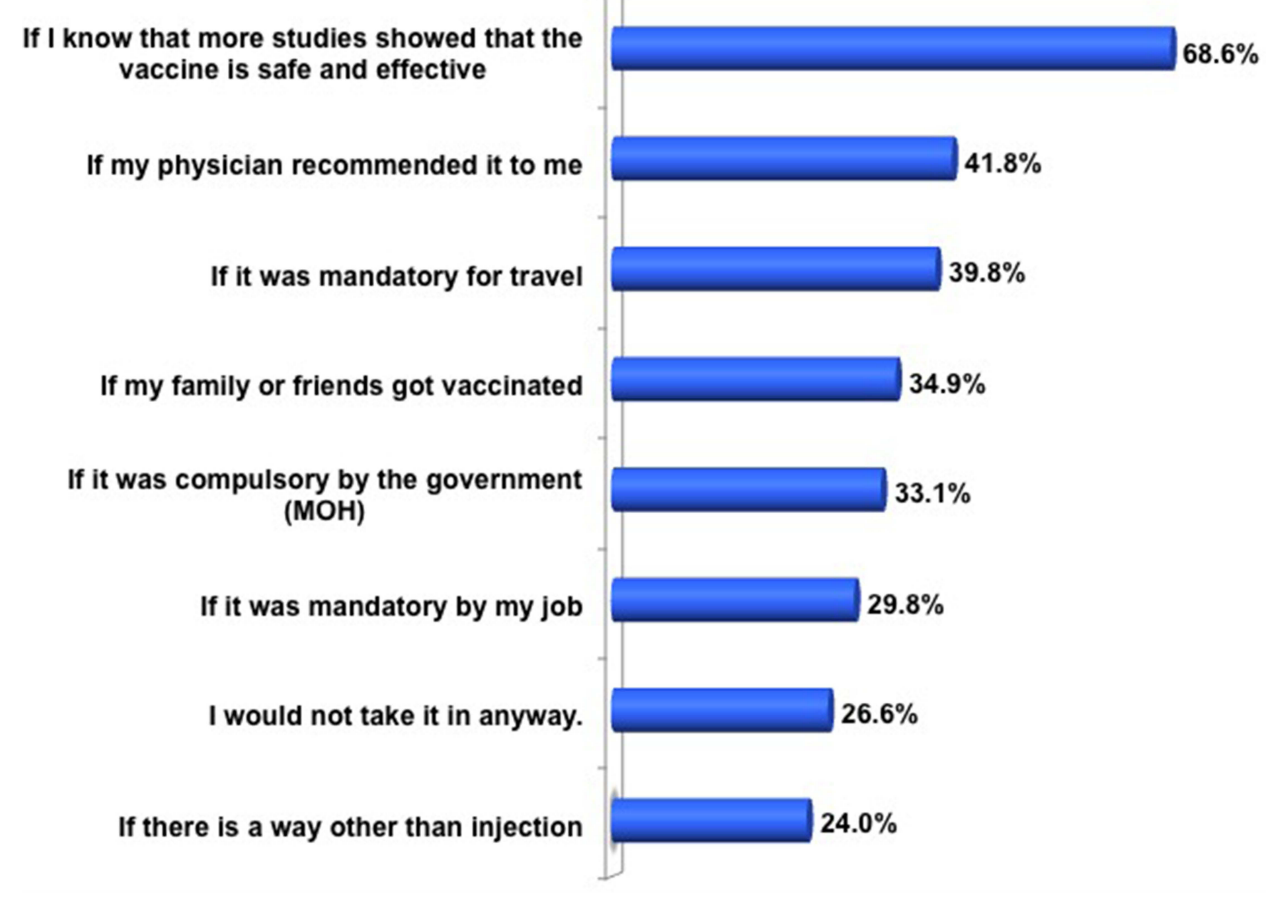

Figure 3 Options to encourage future decision to take COVID-19 Vaccine. 
Table 6 Options to Encourage Uptake COVID-19 Vaccine

\begin{tabular}{|c|c|c|c|}
\hline \multirow[t]{2}{*}{ Studied Groups Options } & \multicolumn{3}{|c|}{ Decision to Take COVID-19 Vaccine $N=6588$} \\
\hline & $\begin{array}{c}\text { No/ Not Sure } \\
4810 \\
\text { N (\%) }\end{array}$ & $\begin{array}{c}\text { Yes } \\
\text { I778 } \\
\text { N (\%) }\end{array}$ & $P$ value \\
\hline \multicolumn{4}{|c|}{$\begin{array}{l}\text { If I know that more studies showed that the vaccine is safe and } \\
\text { effective }\end{array}$} \\
\hline - Agree & $2793(58.1 \%)$ & 1725 (97.0\%) & $<0.00 I^{*}$ \\
\hline - Not Sure & $1049(21.8 \%)$ & $42(2.4 \%)$ & \\
\hline - Do not Agree & $968(20.1 \%)$ & II (0.6\%) & \\
\hline \multicolumn{4}{|c|}{ If my physician recommended it to me } \\
\hline - Agree & $1169(24.3 \%)$ & $1586(89.2 \%)$ & $<0.00 I^{*}$ \\
\hline - Not Sure & $1833(38.1 \%)$ & $164(9.2 \%)$ & \\
\hline - Do not Agree & 1808 (37.6\%) & $28(1.6 \%)$ & \\
\hline \multicolumn{4}{|c|}{ If it was mandatory for travel } \\
\hline - Agree & $1215(25.3 \%)$ & 1406 (79.1\%) & $<0.00 I^{*}$ \\
\hline - Not Sure & $1168(24.2 \%)$ & $217(12.2 \%)$ & \\
\hline - Do not Agree & $2427(50.5 \%)$ & 155 (8.7\%) & \\
\hline \multicolumn{4}{|c|}{ If my family or friends got vaccinated } \\
\hline - Agree & $956(19.9 \%)$ & 1344 (75.6\%) & $<0.00 I^{*}$ \\
\hline - Not Sure & $1549(32.2 \%)$ & $311(17.5 \%)$ & \\
\hline - Do not Agree & $2305(47.9 \%)$ & $123(6.9 \%)$ & \\
\hline \multicolumn{4}{|c|}{ If it was compulsory by the government (MOH) } \\
\hline - Agree & $1004(20.9 \%)$ & $1178(66.3 \%)$ & $<0.00 I^{*}$ \\
\hline - Not Sure & $1180(24.5 \%)$ & $323(18.2 \%)$ & \\
\hline - Do not Agree & $2626(54.6 \%)$ & 277 (15.6\%) & \\
\hline \multicolumn{4}{|c|}{ If it was mandatory by my job } \\
\hline - Agree & $85 \mathrm{I}(17.7 \%)$ & $1110(62.4 \%)$ & $<0.00 I^{*}$ \\
\hline - Not Sure & $1244(25.9 \%)$ & $364(20.5 \%)$ & \\
\hline - Do not Agree & $2715(56.4 \%)$ & $304(17.1 \%)$ & \\
\hline \multicolumn{4}{|c|}{ I would not take it in anyway. } \\
\hline - Agree & $1756(36.5 \%)$ & $0(0.0 \%)$ & $<0.00 I^{*}$ \\
\hline - Not Sure & 1918 (39.9\%) & $260(14.6 \%)$ & \\
\hline - Do not Agree & $1136(23.6 \%)$ & $1518(85.4 \%)$ & \\
\hline \multicolumn{4}{|c|}{ If there is a way other than injection } \\
\hline - Agree & $855(17.8 \%)$ & $725(40.8 \%)$ & $<0.001 *$ \\
\hline - Not Sure & I 347 (28.0\%) & 581 (32.7\%) & \\
\hline - Do not Agree & 2608 (54.2\%) & 472 (26.5\%) & \\
\hline
\end{tabular}

Notes: $* \mathrm{P}<0.05$, that is, significant difference between hesitant and willing to take vaccine at the $5 \%$ level of significance.

government instructions and applying preventive measures (eg wearing face coverings and gloves) or because they were young and healthy. In addition, previous infection with SARS-CoV-2 and being needle-phobic were major barriers against acceptance of a COVID-19 vaccine.

In agreement with other studies, ${ }^{16,18,40,48,57}$ a considerable proportion of respondents reported that they would take a COVID-19 vaccine if additional studies confirmed its safety and efficacy. There were significant differences between people who were hesitant about taking the COVID-19 vaccine and other respondents with regard to options to encourage vaccination. A WHO survey in 19 countries revealed that $61.4 \%$ of respondents reported that they would accept their employer's recommendation to have a COVID-19 vaccine. ${ }^{16}$ A more recent study from the USA found that $67 \%$ of respondents said they would accept a COVID-19 vaccine if it was recommended for them. ${ }^{18}$ Conversely, one global survey ${ }^{58,59}$ concluded that compulsory vaccination by employers increased the likelihood of vaccination refusal across participants of different nationalities. Hence, voluntary vaccination promotions are a better option. The involvement of trusted non- 


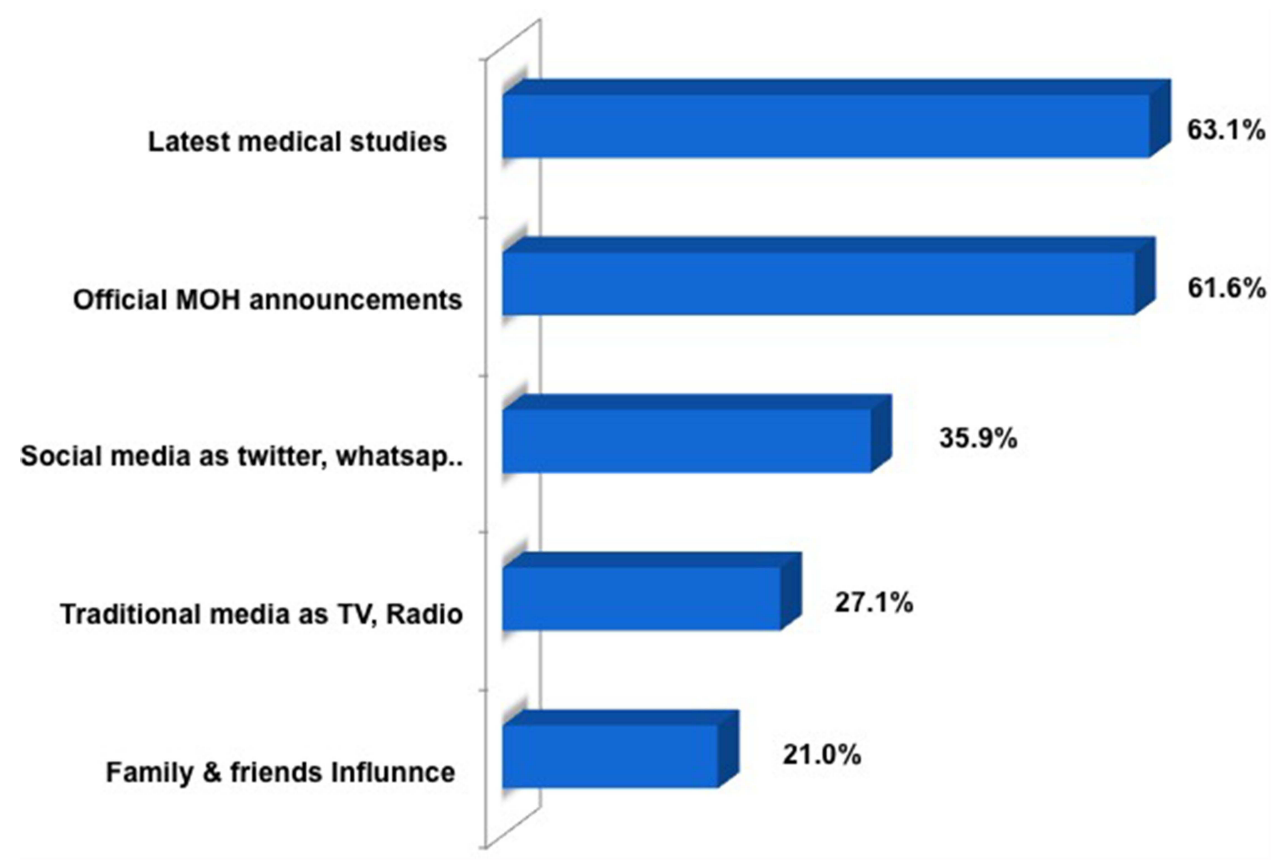

Figure 4 Tools affecting perception towards covid-19 vaccine.

government organizations and community-based groups is crucial to building trust in COVID-19 vaccination. ${ }^{58}$

In accordance with previous findings, the most effective tools affecting perception towards COVID-19 vaccines were reading the latest articles from medical journals, ${ }^{19,53}$ official press releases from the Ministry of Health, ${ }^{15}$ social media, ${ }^{54,55,60}$ traditional media, and advice from family and friends. VH is (at least in part) a problem born of information from media. The overall success of any vaccination program will depend on where and how information about the safety and efficacy of a vaccine is communicated. It will also depend on engagement with, and by, the public. ${ }^{61}$

Our results have implications for the vaccination plans that started at the end of January 2021 in Kuwait. We found that $25.6 \%$ of participants accepted a COVID-19 vaccine, but there were noticeable sociodemographic and geographic disparities for COVID-19-vaccine acceptance. Inconsistent communication from public-health experts, politicians, and social-media "influencers" affected uptake of COVID-19 vaccines. Thus, future communication strategies to build understanding and acceptance of COVID-19 vaccines should consider the level of health, scientific, and general literacy in Kuwait, identify locally trusted sources of information with credible spokespeople, proffer local engagement, accurate information and technological support, and go beyond simply pronouncing that vaccines are safe and efficacious.

\section{Strength and Limitations}

Our survey was conducted in the context of a highly dynamic and changing landscape, with daily variations in perceived disease threat and COVID-19-vaccine development. The true intention regarding COVID-19-vaccine uptake could be different upon provision of sufficient amounts of different types of COVID-19 vaccines. Another key limitation of the study was the sampling strategy, which may not represent the true picture of the Kuwaiti population. However, during the preparation and study period (lockdown due to COVID-19), this was the best method to collect data from a large population to overcome this limitation. Given the non-random, selfselecting nature of the sample, and lack of information regarding who was invited to participate in the survey and why, the results cannot be generalized beyond those of our respondents. Because it was an online survey-based study, the results are subject to recall, and we could not check the accuracy of participants' responses. Moreover, participants needed access to a smartphone/computer to participate, which may have excluded less technology-savvy people. This was a cross-sectional study, therefore a "snapshot" taken at a point in time and the associations identified would hamper interpretation.

Despite the limitations stated above, our study was the first of its kind in Kuwait. It had a large sample size from 
across Kuwait, and used a "snowball sampling" recruitment method that demonstrated a population's intention to take a COVID-19 vaccine and barriers towards COVID-19 vaccination. The study was easy to setup, inexpensive, and conducted before COVID-19 vaccines were introduced in Kuwait. We were able to document the low prevalence of COVID-19-vaccine acceptance, which is important for public-health planning and allocating health resources. We examined a wide range of demographic factors (eg non-Kuwaiti nationality and different occupations) to predict VH. Importantly, our study helped to fill a knowledge gap regarding $\mathrm{VH}$ outside Western countries.

\section{Conclusions}

This research provides a snapshot into hesitancy towards COVID-19 vaccination in Kuwait. Data suggest that considerable vaccine hesitancy persists as 50.8\% not willing to take the vaccine or $23.5 \%$ not sure about it, even with the widespread availability of highly effective and safe immunization strategies. The decision to take a COVID-19 vaccine was significantly positively associated with younger age, being male, having a higher education level, having seasonal influenza vaccination previously, being a non-Kuwaiti, being a healthcare worker and working in the private sector. These alarming results should stir further studies on the root causes and the need of awareness campaigns by Kuwait health authorities. Vaccine literacy interventions including health education targeting various sociodemographic groups offering transparent information about the safety and efficacy of the vaccines and the technology that was utilized in the vaccine production should be taken as a priority to increase the COVID-19 vaccine uptake behavior in the country.

\section{Acknowledgments}

The authors acknowledge all people who agreed to participate in this survey.

\section{Funding}

Self- Funded Research.

\section{Disclosure}

The authors report no conflicts of interest in this work.

\section{References}

1. Zhan M, Qin Y, Xue X, Zhu S. Death from Covid-19 of 23 health care workers in China. $N$ Engl J Med. 2020;382(23):2267-2268. doi:10.1056/NEJMc2005696

2. Alsharji KE. Anxiety and depression during the COVID-19 pandemic in Kuwait: the importance of physical activity. Middle East Curr Psychiatry. 2020;27(1):1-8. doi:10.1186/s43045-020-00065-6

3. WHO. Update on COVID-19. 2021; Available from: www.who.int/ publications $/ \mathrm{m} /$ item/weekly-epidemiological-update-on-covid-1917-august-2021. Accessed November 30, 2021.

4. Polack FP, Thomas SJ, Kitchin N, et al. Safety and efficacy of the BNT162b2 mRNA Covid-19 vaccine. $N$ Engl J Med. 2020;383 (27):2603-2615. doi:10.1056/NEJMoa2034577

5. MacDonald NE. SAGE Working Group on Vaccine Hesitancy. Vaccine hesitancy: definition, scope and determinants. Vaccine. 2015;33(34):4161-4164. doi:10.1016/j.vaccine.2015.04.036

6. Wiyeh AB, Cooper S, Jaca A, Mavundza E, Ndwandwe D, Wiysonge CS. Social media and HPV vaccination: unsolicited public comments on a Facebook post by the Western Cape Department of Health provide insights into determinants of vaccine hesitancy in South Africa. Vaccine. 2019;37(43):6317-6323. doi:10.1016/j. vaccine.2019.09.019

7. Wilson SL, Wiysonge C. Social media and vaccine hesitancy. BMJ Global Health. 2020;5(10):e004206. doi:10.1136/bmjgh-2020004206

8. Cooper S, Betsch C, Sambala EZ, Mchiza N, Wiysonge CS. Vaccine hesitancy-a potential threat to the achievements of vaccination programmes in Africa. Hum Vaccin Immunother. 2018;14 (10):2355-2357. doi:10.1080/21645515.2018.1460987

9. Betsch C, Habersaat KB, Deshevoi S, et al. Sample study protocol for adapting and translating the $5 \mathrm{C}$ scale to assess the psychological antecedents of vaccination. BMJ Open. 2020;10(3):e034869. doi:10.1136/bmjopen-2019-034869

10. WHO. Ten Threats to Global Health in 2019. 2019; Available from: https://www.who.int/newsroom/spotlight/ten-threats-to-global-healthin-2019. Accessed November 30, 2021.

11. Wiyeh AB, Cooper S, Nnaji CA, Wiysonge CS. Vaccine hesitancy 'outbreaks': using epidemiological modeling of the spread of ideas to understand the effects of vaccine related events on vaccine hesitancy. Expert Rev Vaccines. 2018;17(12):1063-1070. doi:10.1080/ 14760584.2018.1549994

12. World Health Organization. An ad hoc WHO technical consultation managing the COVID-19 infodemic: Call for action, 7-8 April 2020. World Health Organization; 2020.

13. Betsch C, Schmid P, Heinemeier D, Korn L, Holtmann C, Böhm R. Beyond confidence: development of a measure assessing the $5 \mathrm{C}$ psychological antecedents of vaccination. PLoS One. 2018;13(12): e0208601. doi:10.1371/journal.pone.0208601

14. Larson HJ, Clarke RM, Jarrett C, et al. Measuring trust in vaccination: a systematic review. Hum Vaccin Immunother. 2018;14 (7):1599-1609. doi:10.1080/21645515.2018.1459252

15. Al-Mistarehi A-H, Kheirallah KA, Yassin A, et al. Determinants of the willingness of the general population to get vaccinated against COVID-19 in a developing country. Clin Exp Vaccine Res. 2021;10 (2):171. doi:10.7774/cevr.2021.10.2.171

16. Lazarus JV, Ratzan S, Palayew A, Gostin L, Larson H, Rabin K. Hesitant or not. A global survey of potential acceptance of a COVID-19 vaccine. medRxiv. 2020.

17. Thunstrom L, Ashworth M, Finnoff D, Newbold S Hesitancy towards a COVID-19 Vaccine and Prospects for Herd Immunity. 2020. Available from: https://ssrn.com/abstract. Accessed November 30, 2021. 
18. Szilagyi PG, Thomas K, Shah MD, et al. National trends in the US public's likelihood of getting a COVID-19 vaccine-April 1 to December 8, 2020. JAMA. 2021;325(4):396-398. doi:10.1001/ jama.2020.26419

19. Al-Sanafi M, Sallam M. Psychological determinants of covid-19 vaccine acceptance among healthcare workers in Kuwait: a cross-sectional study using the $5 \mathrm{c}$ and vaccine conspiracy beliefs scales. Vaccines. 2021;9(7):701. doi:10.3390/vaccines9070701

20. Al-Mohaithef M, Padhi BK. Determinants of COVID-19 vaccine acceptance in Saudi Arabia: a web-based national survey. J Multidiscip Healthc. 2020;13:1657. doi:10.2147/JMDH.S276771

21. Alqudeimat Y, Alenezi D, AlHajri B, et al. Acceptance of a COVID-19 vaccine and its related determinants among the general adult population in Kuwait. Med Principles Practice. 2021;30 (3):262-271. doi:10.1159/000514636

22. AlAwadhi E, Zein D, Mallallah F, Haider NB, Hossain A. Monitoring COVID-19 Vaccine Acceptance in Kuwait During the Pandemic: results from a National Serial Study. Risk Manag Healthc Policy. 2021;14:1413. doi:10.2147/RMHP.S300602

23. Taylor S, Landry CA, Paluszek MM, Groenewoud R, Rachor GS, Asmundson GJ. A proactive approach for managing COVID-19: the importance of understanding the motivational roots of vaccination hesitancy for SARS-CoV2. Front Psychol. 2020;11:2890. doi:10.3389/fpsyg.2020.575950

24. Fisher KA, Bloomstone SJ, Walder J, Crawford S, Fouayzi H, Mazor KM. Attitudes toward a potential SARS-CoV-2 vaccine: a survey of US adults. Ann Intern Med. 2020;173(12):964-973. doi:10.7326/M20-3569

25. Romer D, Jamieson KH. Conspiracy theories as barriers to controlling the spread of COVID-19 in the US. Soc Sci Med. 2020;263:113356. doi:10.1016/j.socscimed.2020.113356

26. Roozenbeek J, Schneider CR, Dryhurst S, et al. Susceptibility to misinformation about COVID-19 around the world. Royal Soc Open Sci. 2020;7(10):201199. doi:10.1098/rsos.201199

27. Bauchner H, Malani PN, Sharfstein J. Reassuring the public and clinical community about the scientific review and approval of a COVID-19 vaccine. JAMA. 2020;324(13):1296-1297. doi:10.1001/ jama.2020.18860

28. Neumann-Böhme S, Varghese NE, Sabat I, et al. Once we have it, will we use it? A European survey on willingness to be vaccinated against COVID-19. Springer. 2020.

29. Reiter PL, Pennell ML, Katz ML. Acceptability of a COVID-19 vaccine among adults in the United States: how many people would get vaccinated? Vaccine. 2020;38(42):6500-6507. doi:10.1016/j. vaccine.2020.08.043

30. Head KJ, Kasting ML, Sturm LA, Hartsock JA, Zimet GD. A national survey assessing SARS-CoV-2 vaccination intentions: implications for future public health communication efforts. Sci Commun. 2020;42(5):698-723. doi:10.1177/1075547020960463

31. Malik AA, McFadden SM, Elharake J, Omer SB. Determinants of COVID-19 vaccine acceptance in the US. EClinicalMedicine. 2020;26:100495. doi:10.1016/j.eclinm.2020.100495

32. Daly M, Robinson E. Willingness to vaccinate against COVID-19 in the US: longitudinal evidence from a nationally representative sample of adults from April-October 2020. medRxiv. 2020.

33. Wang K, Wong EL-Y, Ho K-F, et al. Change of willingness to accept COVID-19 vaccine and reasons of vaccine hesitancy of working people at different waves of local epidemic in Hong Kong, China: repeated cross-sectional surveys. Vaccines. 2021;9(1):62. doi:10.3390/vaccines 9010062

34. Kwok KO, Li KK, Chan HHH, et al. Community responses during early phase of COVID-19 epidemic, Hong Kong. Emerg Infect Dis. 2020;26(7):1575. doi:10.3201/eid2607.200500

35. Sallam M. COVID-19 vaccine hesitancy worldwide: a concise systematic review of vaccine acceptance rates. Vaccines. 2021;9(2):160. doi:10.3390/vaccines 9020160
36. Dagan N, Barda N, Kepten E, et al. BNT162b2 mRNA Covid-19 vaccine in a nationwide mass vaccination setting. $N$ Engl $J$ Med. 2021;384(15):1412-1423. doi:10.1056/NEJMoa2101765

37. Randolph HE, Barreiro LB. Herd immunity: understanding COVID-19. Immunity. 2020;52(5):737-741. doi:10.1016/j. immuni.2020.04.012

38. Kwok KO, Lai F, Wei WI, Wong SYS, Tang JW. Herd immunityestimating the level required to halt the COVID-19 epidemics in affected countries. J Infect. 2020;80(6):e32-e33. doi:10.1016/j. jinf.2020.03.027

39. Sanche S, Lin YT, Xu C, Romero-Severson E, Hengartner NW, Ke R. The novel coronavirus, $2019-\mathrm{nCoV}$, is highly contagious and more infectious than initially estimated. arXiv preprint arXiv. 2020.

40. Magadmi RM, Kamel FO. Beliefs and barriers associated with COVID-19 vaccination among the general population in Saudi Arabia. BMC Public Health. 2021;21(1):1-8. doi:10.1186/s12889021-11501-5

41. Sallam M, Dababseh D, Eid H, et al. Low covid-19 vaccine acceptance is correlated with conspiracy beliefs among university students in Jordan. Int $J$ Environ Res Public Health. 2021;18(5):2407. doi:10.3390/ijerph18052407

42. Sallam M, Dababseh D, Yaseen A, et al. Conspiracy beliefs are associated with lower knowledge and higher anxiety levels regarding COVID-19 among students at the University of Jordan. Int J Environ Res Public Health. 2020;17(14):4915. doi:10.3390/ijerph17144915

43. Sallam M, Dababseh D, Yaseen A, et al. COVID-19 misinformation: mere harmless delusions or much more? A knowledge and attitude cross-sectional study among the general public residing in Jordan. PLoS One. 2020;15(12):e0243264. doi:10.1371/journal.pone.0243264

44. Robertson E, Reeve KS, Niedzwiedz CL, et al. Predictors of COVID-19 vaccine hesitancy in the UK household longitudinal study. Brain Behav Immun. 2021;94:41-50. doi:10.1016/j. bbi.2021.03.008

45. Ward JK, Peretti-Watel P, Bocquier A, Seror V, Verger P. Vaccine hesitancy and coercion: all eyes on France. Nat Immunol. 2019;20 (10):1257-1259. doi:10.1038/s41590-019-0488-9

46. El-Elimat T, AbuAlSamen MM, Almomani BA, Al-Sawalha NA, Alali FQ. Acceptance and attitudes toward COVID-19 vaccines: a cross-sectional study from Jordan. PLoS One. 2021;16(4):e250555. doi:10.1371/journal.pone. 0250555

47. Alabdulla M, Reagu SM, Al-Khal A, Elzain M, Jones RM. COVID19 vaccine hesitancy and attitudes in Qatar: a national cross-sectional survey of a migrant-majority population. Influenza Other Respi Viruses. 2021;15(3):361-370. doi:10.1111/irv.12847

48. Fu C, Wei Z, Pei S, Li S, Sun X, Liu P. Acceptance and preference for COVID-19 vaccination in health-care workers (HCWs). MedRxiv. 2020;1:584.

49. Szmyd B, Karuga FF, Bartoszek A, et al. Attitude and behaviors towards SARS-CoV-2 vaccination among healthcare workers: a cross-sectional study from Poland. Vaccines. 2021;9(3):218. doi:10.3390/vaccines 9030218

50. Paterson P, Meurice F, Stanberry LR, Glismann S, Rosenthal SL, Larson HJ. Vaccine hesitancy and healthcare providers. Vaccine. 2016;34(52):6700-6706. doi:10.1016/j.vaccine.2016.10.042

51. Kwok KO, Li -K-K, Wei WI, Tang A, Wong SYS, Lee SS. Influenza vaccine uptake, COVID-19 vaccination intention and vaccine hesitancy among nurses: a survey. Int J Nurs Stud. 2021;114:103854. doi:10.1016/j.ijnurstu.2020.103854

52. Qattan A, Alshareef N, Alsharqi O, Al Rahahleh N, Chirwa GC, AlHanawi MK. Acceptability of a COVID-19 vaccine among healthcare workers in the Kingdom of Saudi Arabia. Front Med. 2021;8:83. doi: $10.3389 /$ fmed.2021.644300

53. Fares S, Elmnyer MM, Mohamed SS, Elsayed R. COVID-19 Vaccination Perception and Attitude among Healthcare Workers in Egypt. J Prim Care Community Health. 2021;12:21501327211013303. doi:10.1177/21501327211013303 
54. Biddlestone M, Green R, Douglas KM. Cultural orientation, power, belief in conspiracy theories, and intentions to reduce the spread of COVID-19. Br J Soc Psychol. 2020;59(3):663-673. doi:10.1111/ bjso. 12397

55. Douglas KM. COVID-19 conspiracy theories. Group Proc Intergroup Relations. 2021;24(2):270-275. doi:10.1177/ 1368430220982068

56. Sallam M, Dababseh D, Eid H, et al. High rates of COVID-19 vaccine hesitancy and its association with conspiracy beliefs: a study in Jordan and Kuwait among other Arab countries. Vaccines. 2021;9(1):42. doi:10.3390/vaccines9010042

57. Kreps S, Prasad S, Brownstein JS, et al. Factors associated with US adults' likelihood of accepting COVID-19 vaccination. JAMA Network Open. 2020;3(10):e2025594-e2025594. doi:10.1001/ jamanetworkopen.2020.25594
58. Mello MM, Abiola S, Colgrove J. Pharmaceutical companies' role in state vaccination policymaking: the case of human papillomavirus vaccination. Am J Public Health. 2012;102(5):893-898. doi:10.2105/ AJPH.2011.300576

59. Mello MM, Silverman RD, Omer SB. Ensuring uptake of vaccines against SARS-CoV-2. N Engl J Med. 2020;383(14):1296-1299.58. doi:10.1056/NEJMp2020926

60. Amazeen MA, Benevenuto F, Brashier NM, et al. Tackling misinformation: what researchers could do with social media data. Harvard Kennedy School Misinformation Rev. 2020;1(8). doi:10.37016/mr2020-38

61. Chadwick A, Kaiser J, Vaccari C, et al. Online social endorsement and Covid-19 vaccine hesitancy in the United Kingdom. Social Media. 2021;7(2):20563051211008817.
Risk Management and Healthcare Policy

\section{Publish your work in this journal}

Risk Management and Healthcare Policy is an international, peerreviewed, open access journal focusing on all aspects of public health, policy, and preventative measures to promote good health and improve morbidity and mortality in the population. The journal welcomes submitted papers covering original research, basic science, clinical \& epidemiological studies, reviews and evaluations,

\section{Dovepress}

guidelines, expert opinion and commentary, case reports and extended reports. The manuscript management system is completely online and includes a very quick and fair peer-review system, which is all easy to use. Visit http://www.dovepress.com/testimonials.php to read real quotes from published authors. 